\title{
Hölzl, Richard, Umkämpfte Wälder. Die Geschichte der ökologischen Reform in Deutschland 1760-1860
}

\section{Guillaume Garner}

\section{OpenEdition}

\section{Journals}

Édition électronique

URL : http://journals.openedition.org/ifha/6500

DOI : $10.4000 /$ ifha. 6500

ISSN : 2198-8943

Éditeur

IFRA - Institut franco-allemand (sciences historiques et sociales)

Référence électronique

Guillaume Garner, «Hölzl, Richard, Umkämpfte Wälder. Die Geschichte der ökologischen Reform in Deutschland 1760-1860», Revue de l'IFHA [En ligne], Date de recension, mis en ligne le 01 janvier 2012, consulté le 22 septembre 2020. URL : http://journals.openedition.org/ifha/6500 ; DOI : https://doi.org/ $10.4000 /$ ifha. 6500

Ce document a été généré automatiquement le 22 septembre 2020.

(C)IFHA 


\title{
Hölzl, Richard, Umkämpfte Wälder. Die Geschichte der ökologischen Reform in Deutschland 1760-1860
}

\author{
Guillaume Garner
}

1 Dans de nombreux États allemands, la forêt et ses ressources deviennent entre le milieu du XVIIIe siècle et le milieu du XIXe siècle un enjeu majeur de débats scientifiques, économiques, politiques, en même temps qu'elles fournissent un motif essentiel à la contestation sociale, l'un des moteurs de cette « guerre pour la forêt » (p. 415) étant les réformes élaborées et progressivement mises en œuvre par les gouvernements et les administrations à partir de l'époque des Lumières. C'est ce processus complexe que R.H. entend étudier à partir du cas de la Bavière qui est l'un des foyers de la « science forestière » (Forstwissenschaft) naissante et dans laquelle les efforts réformateurs de l'administration furent particulièrement soutenus.

2 L'originalité majeure de cette remarquable étude est de croiser deux approches souvent dissociées : celle de l'histoire des sciences, qui étudie la constitution du discours de la réforme forestière et les débats qui s'y greffent, et celle de l'histoire socioculturelle des pratiques puisque R.H. choisit deux terrains d'observation (le Zellertal en Basse-Bavière et le Spessart en Franconie) pour étudier à l'échelle locale la manière dont les réformes ont été appliquées et dont les populations concernées y ont réagi. À côté de sources discursives et savantes (englobant caméralisme, "économie forestière " et science forestière), l'auteur mobilise également des sources administratives et judiciaires (pour étudier la délinquance forestière). Cette double approche fonde l'intérêt et la réussite d'une étude (en dépit de l'absence de toute carte) qui se distingue par une exploitation très minutieuse des sources, abondamment citées, et la mobilisation d'une bibliographie abondante à laquelle on peut cependant reprocher de quelque peu négliger l'historiographie anglo-saxonne (par exemple les travaux de Paul Warde).

Dans une première partie, R.H. montre comment s'élabore dans les années 1760-1810 un discours de la réforme forestière, fondé sur le risque d'une pénurie de bois à venir ; ce discours identifie des coupables (les populations paysannes et les garde-forestiers) et 
propose des solutions qui tournent autour du concept de durabilité (Nachhaltigkeit) : celle-ci sera garantie par une exploitation rationnelle des surfaces forestières, conciliant exploitation et régénération des essences, ainsi que par l'élimination des droits et usages coutumiers des populations rurales et une démarcation stricte entre espaces forestiers et espaces agricoles (notamment d'élevage). Conscients de la difficulté d'appliquer ces mesures, les auteurs réformateurs (publicistes et/ou membres de l'administration bavaroise) soulignent la nécessité de mettre en place une administration structurée et une formation à ces pratiques des futurs garde-forestiers. Cette partie souligne également de manière convaincante comment ce discours a bâti sa légitimité et s'est imposé en récit dominant, à partir d'une double insertion, dans les rouages de l'administration d'État et dans les réseaux de la République des Lettres allemande et européenne.

4 De loin la plus vaste (p. 167-414), la deuxième partie s'attache à étudier l'application des réformes sur place, dans le Zellertal et dans le Spessart. Dans le premier cas, la forêt sert de réserve en ressources diverses à une population rurale qui tire l'essentiel de ses revenus d'activités agricoles. Les réformes menées visent à la fois abolir les usages et droits coutumiers et à mettre en place une exploitation rationnelle, "durable " des espaces. Les populations réagissent à ces mesures par de nombreuses plaintes, des procès visant à donner un statut juridique à leurs usages, et affirment derrière ces réactions une identité collective villageoise, fondée sur la nécessité d'assurer à tous la couverture des besoins domestiques élémentaires - même si, dans le même temps, une partie des paysans tente également de profiter des chances offertes par les mesures de privatisation des forêts engagées au début du XIXe siècle. En revanche, dans le Spessart, que la Bavière possède à partir de 1814 et dont le gouvernement entend faire une forêt " moderne " à même de répondre à une demande croissante, les ressources forestières sont vitales pour les populations locales, ce qui explique une résistance plus forte aux mesures prises, illustrée par une délinquance forestière qui va croissant jusqu'aux années 1848-1849. Dans les deux cas, la réforme n'apparaît pas comme un processus linéaire imposé d'en haut, mais subit des inflexions, des adaptations qui résultent selon R.H. d'un processus de négociation plus ou moins formel entre les populations locales et des autorités elles-mêmes parfois divisées.

5 Plus brève, la troisième partie revient sur les discours tenus à propos de ces réformes dans les années 1800-1860. La littérature et une partie de l'opinion publique sont rendues sensibles à ce thème par la délinquance, les débats tournant autour d'impératifs et d'objectifs en partie contradictoires : la nécessité d'assurer la rentabilité économique des forêts, la volonté de créer les conditions d'un « marché du bois » tout en évitant une trop forte augmentation des prix et en atténuant les conséquences sociales de la politique menée. L'auteur souligne enfin qu'il faut attendre les années 1850-60 pour voir émerger un discours qui souligne l'importance de la forêt dans " l'économie de la nature ", son effet bénéfique sur la qualité de l'air, et qui thématise la question de la protection des forêts : autant de thèmes qui contribuent à relégitimer et en même temps à redéfinir la politique en matière de forêts.

Guillaume Garner (ENS Lyon) 